Rhodieleen Anne R. de la Cruz, MD' Rene S. Tuazon, $\mathrm{MD}^{2}$

\section{'Department of Otorhinolaryngology}

Philippine General Hospital

University of the Philippines Manila

${ }^{2}$ Department of Otorhinolaryngology College of Medicine - Philippine General Hospital

University of the Philippines Manila
Correspondence: Dr. Rene S. Tuazon Department of Otorhinolaryngology Ward 10, Philippine General Hospital University of the Philippines Manila Taft Avenue, Ermita, Manila 1000 Philippines

Phone (632) 5548467

Email: rstuazonmd@gmail.com

Reprints will not be available from the author.

The authors declared that this represents original material that is not being considered for publication or has not been published or accepted for publication elsewhere in full or in part, in print or electronic media; that the manuscript has been read and approved by the authors, that the requirements for authorship have been met by each author, and that the authors believe that the manuscript represents honest work.

The authors signed disclosures that there are no financial or other (including personal) relationships, intellectual passion, political or religious beliefs, and institutional affiliations that might lead to a conflict of interest.

Presented at the Philippine Society of Otolaryngology Head and Neck Surgery Descriptive Research Contest. September 18, 2014. Natrapharm, The Patriot Building, Parañaque City.

\section{Motorcycle Related Cranio-Maxillofacial Injuries at a Tertiary Hospital in the Philippines}

\author{
ABSTRACT \\ Objective: To describe the type and determine the number of motorcycle related cranio- \\ maxillofacial injuries that were seen by the ORL service in the emergency room of a tertiary \\ hospital from January 2013 to December 2013.

\section{Methods:} \\ Design: Cross sectional retrospective chart review \\ Setting: $\quad$ Tertiary National University Hospital \\ Participants: One hundred nine (109) charts of patients seen at the emergency \\ room from January 2013 to December 2013 were reviewed
}

Results: Of the 109 charts of patients involved in vehicular accidents, there were 76 documented cases of motorcycle related accidents. Of these, $91 \%$ involved males and $9 \%$ involved females. Seventy one percent (71\%) did not wear helmets, of whom $36 \%$ were young adult males between the ages of 18-30 years. Those that wore helmets had a total of 27 different facial fracture sites: $19 \%$ zygomatic tripod fractures, $15 \%$ temporal bone fractures and $11 \%$ with no fractures noted. Among those who did not wear helmets 75 fractures were noted. Twenty four percent (24\%) were tripod fractures, $15 \%$ temporal bone fractures and $12 \%$ maxillary fractures. Only one did not incur any fractures.

Conclusion: Most cranio-maxillofacial fractures seen at the emergency room were from motorcycle related injuries (70\%). Despite implementation of Republic Act 10054 (The Motorcycle Helmet Act of 2009) majority of motorcycle-related accidents are still incurred by riders without helmets.

Keywords: cranio-maxillofacial fractures, motorcycle accidents, helmet, tripod fracture, temporal bone fracture

Motorcycles have become an increasingly popular form of transportation due to their low cost in fuel consumption and flexibility in avoiding traffic conditions in the metropolitan area. However, this type of transport is the top cause of fatal and nonfatal injuries in vehicular accidents.

Several studies have shown that the use of helmets decreased the incidence of fatal and nonfatal injuries. ${ }^{2-5}$ The enactment of the universal helmet law also decreased hospital admissions for motorcycle related injuries. ${ }^{2-5}$ In the Philippines, the Motorcycle Helmet Act was signed into 
law in March 2010. ${ }^{6}$ Despite the enactment of this law there have still been numerous cases of motorcycle related accidents without helmet use. ${ }^{7}$ As, such there is a need to collect epidemiological data on the frequency of helmet use among motorcyclists. Determining the number of motorcycle accidents, demographics, frequency of helmet use and type of injuries may assist in formulating a program to increase awareness of the law and its provisions, and lessen injuries from road accidents.

The aim of this study was to determine the following: 1) frequency of helmet use in drivers or riders involved in motorcycle accidents; 2 ) the number of motorcycle-related cranio-maxillofacial injuries; 3 ) type of cranio-maxillofacial fracture incurred by patients who were helmets users versus non-users; and 4) mechanisms of injury.

\section{METHODS}

With institutional ethical review board approval, a retrospective cross sectional chart review of cases involving vehicular accidents between January 1 and December 31, 2013 was conducted. Charts were retrieved from the hospital medical records section using the patient's case number and name obtained from the emergency room census.

Included were records of those 1) referred to the otorhinolaryngology Emergency Room (ORL ER) service from January 2013 to December 2013; 2) who were drivers and passengers involved in motorcycle accidents; and 3) who underwent radiographic tests. Excluded were records of patients 1) who absconded or went home against advice before they underwent radiographic tests; 2 ) who were involved in other types of vehicular accidents; and 3) involved in motorcycle accidents but not referred to the ORL service. A data abstraction sheet was used to encode data from the charts.

Data regarding qualitative variables were summarized using frequencies and percentages. Quantitative data were summarized using mean, standard deviation and these were analyzed using Microsoft Excel 2010 Version 14.0.7015.1000 SP2 (Microsoft Corp., Redmond, WA, USA).

\section{RESULTS}

Of the 121 charts of patients incurring cranio-maxillofacial injuries initially retrieved from the medical records section, 109 charts of patients meeting inclusion and exclusion criteria were involved in vehicular accidents. Seventy-six (70\%) of these were motorcycle related. There were 69 males and 7 females, with ages ranging 14-60 years old. Demographic data of the patients are summarized in Table 1.

Only $29 \%$ of the patients in the charts reviewed wore a helmet during the time of the accident. Most of the patients who did not wear helmets were between the ages of 18-30 years old and those that did wear helmets were mostly between the ages of 31-50 years old. Males and females showed the same trend of helmet use.

Cranio-maxillofacial fractures were noted for all the charts reviewed. Most patients had multiple fracture sites resulting in 102 fractures documented for the 76 patients. Seventy-five (75) fracture sites were noted for 54 patients not wearing helmets. Approximately 1.22 fractures

Table 1. Distribution of age according to sex of patients involved in motorcycle accidents $(n=76)$

\begin{tabular}{|l|c|c|c|} 
& Frequency & $\begin{array}{l}\text { Mean age }+/ \text {-Standard } \\
\text { Deviation }\end{array}$ & Range \\
\hline Males & 69 & $30+/-11$ years old & $14-60$ years old \\
\hline Females & 7 & $29+/-11$ years old & $17-47$ years old \\
\hline TOTAL & 76 & $30+/-11$ years old & $14-60$ years old \\
\hline
\end{tabular}

Table 2. Distribution of Mechanism of injury $(n=76)$

\begin{tabular}{|l|c|c|}
\hline Type & Frequency & Percent \\
\hline Motorcycle vs pavement & 39 & 51.32 \\
\hline Motorcycle vs post & 5 & 6.58 \\
\hline Motorcycle vs tricycle & 4 & 5.26 \\
\hline Motorcycle vs bus & 3 & 3.95 \\
\hline Motorcycle vs truck & 3 & 3.95 \\
\hline Motorcycle vs motorcycle & 3 & 3.95 \\
\hline Motorcycle vs gutter & 2 & 2.63 \\
\hline Motorcycle vs car & 2 & 2.63 \\
\hline Motorcycle vs jeep & 2 & 2.63 \\
\hline Unknown mechanism & 1 & 1.32 \\
\hline Motorcycle vs building & 1 & 1.32 \\
\hline Motorcycle vs canal & 1 & 1.32 \\
\hline Motorcycle vs wire & 1 & 1.32 \\
\hline Motorcycle vs pedestrian & 1 & 1.32 \\
\hline Motorcycle vs wall & 1 & 1.32 \\
\hline Motorcycle vs truck & 1 & 1.32 \\
\hline Motorcycle vs van & 1 & 1.32 \\
\hline Motorcycle vs taxi & 1 & 1.32 \\
\hline Motorcycle vs plant box & 1 & 1.32 \\
\hline Motorcycle vs dog & 1 & 1.32 \\
\hline Motorcycle vs tree & 1 & 1.32 \\
\hline Motorcycle vs rock & 1 & 1.32 \\
\hline TOTAL & 76 & 100.00 \\
\hline
\end{tabular}


per patient with helmets were observed while 1.37 fractures per patient were sustained by those who did not wear helmets. Only 1 out of the 54 patients without helmets had no fractures.

The most common fractures incurred by patients with and without helmets are described in Figures 1 and 2.

There were several mechanisms of injury noted for the charts reviewed. Motorcycle riders hit the pavement causing craniomaxillofacial fractures more than $50 \%$ of the time. (Table 2)

\section{DISCUSSION}

Our study showed that $70 \%$ of vehicle related accidents are due to motorcycle use and the frequency of helmet use was low. Tripod and temporal bone fractures were commonly seen for patients in motorcycle

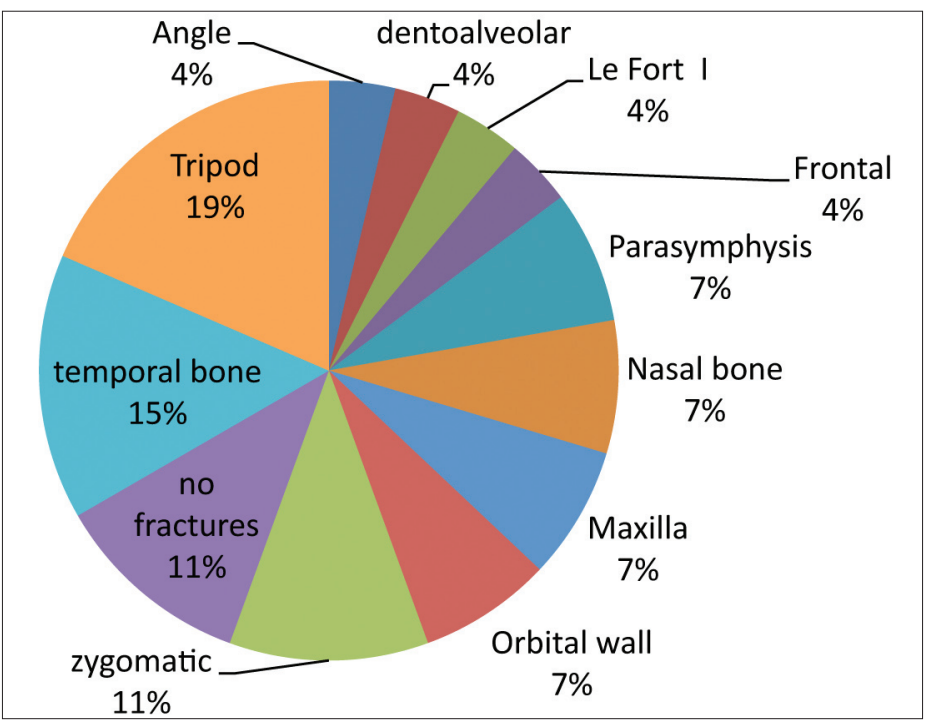

Figure 1. Most common fractures of patients with helmets during motorcycle accidents ( $n=27$ )



Figure 2. Most common fractures of patients without helmets during motorcycle accidents. $(n=75)$ accidents regardless of helmet use however more cranio-maxillofacial fractures were seen for patients not wearing helmets. Motorcycle users most commonly hit the pavement, which caused their injuries.

In other developed countries such as Italy there was decrease in hospital admissions for traumatic brain injuries after stricter implementation of the motorcycle helmet law. ${ }^{5}$ A meta-analysis in the United States showed that a universal helmet act does decrease the number of hospital admissions. ${ }^{8}$

The data from our study showed that less than $25 \%$ used helmets during the time of the accident which is well below the values of other developing countries with a universal helmet law. In a similar study in Brazil, $76 \%$ of patients wore helmets during the time of the accident. ${ }^{4}$ Our values were much closer to a study in Jamaica where only $34 \%$ wore helmets. ${ }^{3}$ Even though these three countries had a universal helmet law, its effectiveness was not the same.

For this study, motorcycle accidents with or without helmets were more common in 30-year-old males ( $30+/-11$ years old) and 29 -year-old females ( $29+/-11$ years old). This data is comparable to similar studies in developing countries such as Brazil and Jamaica, except for a younger peak age incidence of 10 to 19 years among female motorcyclists in the former. ${ }^{3,4}$

Motorcycle riders were at a disadvantage when collision occured due to the lack of safety devices like seat belts and air bags. A helmet was the most important safety gear. A prospective cross-sectional study in a trauma center in Jamaica showed a 70\% reduction in injury severity and $40 \%$ reduction in mortality of helmet users as compared to non-helmet users. ${ }^{3}$ A Cochrane review of 53 observational studies concluded that motorcycle helmets reduce the risk of mortality with an Odds Ratio (OR) of $0.58,95 \%$ Confidence Interval $(\mathrm{Cl}) 0.50$ to 0.68 among the 4 crosssectional studies provided. The same review also found that helmets decrease the risk of head injury with an OR of 0.23 to $0.35 .^{9}$

Although insufficient to generate a hypothesis on the impact of helmets on head injuries, our data suggests that when a ratio of the number of fractures per patient is obtained, more fractures were seen per person for the non-helmet group compared to the helmet group. The data also suggests that there were more instances where no fractures were seen for the group who used helmets compared to those who did not use helmets. Although our results were not concurred with by the Brazil study, where more fractures were seen for the groups who wore helmets, this may be because those that did not wear helmets in that study sustained encephalic trauma and treatment for the facial fractures were not prioritized. ${ }^{4}$

Helmets may not always protect riders from facial fractures but have been proven to prevent significant traumatic brain injuries. ${ }^{3}$ In the study in Jamaica, those who did not wear helmets had more intracranial lesions (44.7\%) and had more severe traumatic brain injuries (46.8\%). ${ }^{7}$ 


\section{ORIGINAL ARTICLES}

The previously cited study in Brazil noted that mandibular fractures and fractures of the midface were common. ${ }^{4}$ They associated it with the fact that even with helmets there is still a prominence of the mandible and dissipation of forces to the midface. ${ }^{4}$ In contrast, the most common fractures seen for both helmet and non-helmet users in our study were tripod fractures followed by temporal bone fractures. Mandibular fractures were not as common. Temporal bone fractures were also noted in our study but not mentioned in the Brazil study, ${ }_{1}^{4}$ perhaps because they did not consider these part of maxillofacial injuries. Temporal bone fractures were common in both helmet and nonhelmet groups in our study may suggest that helmets do not offer significant protection from this type of fracture.

The study had several limitations. The charts reviewed were limited to those referred to the ORL service at a tertiary hospital in the Philippines from January 2013-December 2013. Records of persons with motorcycle-related injuries that were not referred to our service were not included. Charts not retrieved by the records section were also excluded from data analysis. Radiographic images were not reviewed for confirmation of injuries listed in the charts. The study did not also account for those patients with fatal injuries or those who had traumatic brain injuries that could have been a significant addition to the data gathered.

It is recommended that a prospective study will yield a more valid estimate of the cases referred to our service since we will no longer be dependent on the medical records being complete. It may also be important to note the frequency of use of Department of Trade and Industry (DTI) - approved helmets specifically and to determine the efficacy of these helmets in preventing head injuries. It will also be interesting to determine the efficacy of the different types of helmets in preventing certain facial fractures.

Traffic road accidents are a major public health problem because of the consequences of injuries to riders and destruction of property. Thus, several countries have already passed laws to prevent this, one of which is the universal helmet law. However, compliance to this law has still been low. As evidenced by our study, motorcycle related accidents continue to be a common reason for hospital admission. Most craniomaxillofacial injuries are incurred by those who did not use helmets during the time of the accident. Data from this study can be used for further public health researches to improve health policies on road traffic accident prevention. There is still room for improvement in the implementation of the Motorcycle Helmet Act of 2009.

\section{REFERENCES}

1. AAPhilippines.org [homepage on the Internet]. Philippines: Metro Manila Development Authority. Road Safety Unit Traffic Operations Center. Metro Manila Accident Reporting and Analysis System: Traffic Accident Report January to December Accident Report January to December 2009; [updated 2011 cited 2014 Aug 3]. Available from: http://www.aaphilippines. org/roadsafety/.../MMARAS\%20Annual\%20Report\%202009.pdf.

2. Tsai MC, Hemenway D. Effect of the mandatory helmet law in Taiwan. Inj Prev. 1999 Dec [cited 2014 Aug 3]; 5(4): [290-1]. Available from: http://injuryprevention.bmj.com/content/5/4/290. full . DOI: 10.1136/ip.5.4.290; PubMed PMID: 10628919; PubMed Central PMCID: PMC1730540.

3. Crandon IW, Harding HE, Cawich SO, Frankson MA, Gordon-Strachan G, McLennon N, et al. The impact of helmets on motorcycle head trauma at a tertiary hospital in Jamaica. BMC Res Notes. 2009 Aug. [Cited 2014 Aug 3]; 2(1):[About 5p]. Available from: http://www.biomedcentral. com/1756-0500/2/172. DOI: 10.1186/1756-0500-2-172; PubMed PMID: 19715612; PubMed Central PMCID: PMC2746805.

4. Maliska MC, Borba M, Asprino L, Moraes MD, Moreira RW. Oral and maxillofacial surgery-Helmet and maxillofacial trauma: a 10-year retrospective study. Brazilian Journal of Oral Sciences. [serial on internet] 2012 Jun. [cited 2014 Aug 3];11(2):[125-9]. Available from: http://revodonto. bvsalud.org/scielo.php?script=sci_arttext\&pid=S1677-32252012000200010\&Ing=en.

5. Servadei F, Begliomini C, Gardini E, Giustini M, Taggi F, Kraus J. Effect of Italy's motorcycle helmet law on traumatic brain injuries. Inj Prev. 2003 Sep. [cited 2014 Aug 3]; 9(3):[257-60]. Available from: https://www.ncbi.nlm.nih.gov/pmc/articles/PMC1731012/pdf/v009p00257. pdf. DOI:10.1136/ip.9.3.257; PubMed PMID: 12966016; PubMed Central PMCID: PMC1731012.

6. Senate.gov [homepage on the Internet]. Philippines: Republic of Philippines Congress of the Philippines [Updated 2009 cited 2013 September 2]. Available from: https://www.senate.gov. ph/republic_acts/ra\%2010054.pdf.

7. Official Gazette [homepage on the Internet]. Philippines: Republic of the Philippines Department of health. [updated 2013 cited 2014 August 15]. Available from: http://www.gov. $\mathrm{ph} / 2013 / 04 / 29 / 9$-out-of-10-doa-motorcycle-riders-found-not-wearing-helmet/.

8. MacLeod JB, DiGiacomo JC, Tinkoff G. An evidence-based review: helmet efficacy to reduce head injury and mortality in motorcycle crashes: EAST practice management guidelines. $J$ Trauma. 2010 Nov. [cited 2014 Aug 3]; 69(5): [1101-11]. Available from: http://journals.Iww.com/ jtrauma/Citation/2010/11000/An_Evidence_Based_Review_Helmet_Efficacy_to.12.aspx.DOI: 10.1097/TA.0b013e3181f8a9cc; PubMed PMID: 21068615.

9. Liu BC, Ivers R, Norton R, Boufous S, Blows S, Lo SK. Helmets for preventing injury in motorcycle riders. Cochrane Database Syst Rev. 2008 Jan 23 [cited 2014 Aug 3]. 1(CD004333): [about 44p]. Available from: http:// http://onlinelibrary.wiley.com/doi/10.1002/14651858.CD004333.pub3/ pdf. DOI: 10.1002/14651858.CD004333.pub3; PubMed PMID: 18254047. 